\title{
Type 1 Diabetes Mellitus and Celiac Disease: Distinct Autoimmune Disorders That Share Common Pathogenic Mechanisms
}

\author{
Gregory Goodwin
}

Division of Endocrinology, Department of Pediatrics, Boston Children's Hospital, Harvard Medical School, Boston, MA, USA

\section{Keywords}

Diabetes · Celiac disease · Autoimmunity · Human

lymphocyte antigens · Environment · Microbiome

\begin{abstract}
Background: The relatively common co-occurrence of type 1 diabetes (T1D) and celiac disease (CD) suggests these disorders share common pathogenic etiologies. Summary:T1D and $C D$ are strongly linked to closely related high-risk human lymphocyte antigens (HLA-DR-DQ). High-risk HLA molecules bind specific fragments of gluten or the islet self-antigen(s) and present these antigens to antigen-responsive T cells. In an appropriate proinflammatory environment, the autoimmune response results in destruction of the intestinal enterocyte and/or the pancreatic beta cell. Environmental factors have been implicated in the etiology of T1D and CD because (1) identical twins are only partially concordant for these disorders and (2) incidence rates of T1D and CD have been steadily rising for decades. Prospective studies in infants genetically predisposed to T1D and CD showed that antibody positivity to both disorders begins in the first 1-3 years of life. Viral infections and early exposure to gluten or cow's milk in the infant diet have been implicated in disease pathogenesis. However, delaying introduction of gluten in the infant diet until 12 months of age had no impact on the
\end{abstract}

development of islet or celiac autoimmunity. Weaning nursing infants to hydrolyzed infant formula had no impact on the development of T1D. Viral infections have been suspected of playing a role in T1D pathogenesis for decades. A large international prospective study (TEDDY) has shown increased risk of T1D autoimmunity particularly when $>5$ respiratory infections or febrile infections have occurred in the 9 months preceding the appearance of islet antibodies. Provocative data in animal models of T1D suggest the microbiome may play an important role in the pathogenesis of T1D. Breastfeeding, diet, infections, antibiotics, and method of birth alter the composition of the microbiome. Human data indicate subtle differences in the microbiome of children with T1D autoimmunity, while intestinal dysbiosis has been clearly demonstrated in CD. Alterations of the integrity of the intestinal mucosa plays an important role in the pathogenesis of CD, and the NOD mouse model suggests an important role of a leaky intestinal epithelium in T1D as well. Key Message: Immunogenetics and the environment are closely interrelated in the pathogenesis of T1D and CD. Large welldesigned prospective studies in at-risk populations informed by scientifically rigorous studies in animal models are likely to have the greatest impact on our understanding of the complex pathogenesis of these detrimental autoimmune disorders.

(c) 2019 S. Karger AG, Basel

\section{KARGER}

(c) 2019 S. Karger AG, Basel

karger@karger.com

www.karger.com/hrp
Gregory Goodwin

Division of Endocrinology, Boston Children's Hospital

300 Longwood Ave

Boston, MA 02115 (USA)

E-Mail Gregory.goodwin@ childrens.harvard.edu 


\section{Introduction}

The association of type 1 diabetes (T1D) and celiac disease $(\mathrm{CD})$ has become increasingly recognized, particularly in light of routine screening of T1D patients for CD. Approximately $5 \%$ of patients with T1D will also have CD and T1D usually occurs before CD when both disorders are present in the same patient [1]. The co-occurrence of these two disorders has traditionally been attributed to the sharing of common high-risk human lymphocyte antigen (HLA) genotypes (DR-DQ) [2]. However, recent evidence suggests environmental or nongenetic factors play an important role in the association of these disorders [2,3]. This review will present an overview of the salient clinical aspects of $C D$ in patients with T1D followed by a discussion of the leading clinical and basic research relevant to the co-occurrence of these disorders.

\section{Clinical Overview: Screening, Diagnosis, Treatment, Outcomes}

Patients with T1D are at increased risk for developing $\mathrm{CD}[1,2]$. The risk of T1D patients developing CD is approximately $5 \%$, while the risk for $\mathrm{CD}$ in the general population is $\sim 1 \%[1,2,4]$. Worldwide, the risk of CD coexisting with $\mathrm{T} 1 \mathrm{D}$ varies with prevalence rates of $1.6 \%$ in France, 2.4\% in Finland, 9.7\% in Sweden, and 11.1\% in North India [1,3]. Hence, expert clinical practice guidelines recommend screening all pediatric and adolescent T1D patients soon after diagnosis and again at 2 and 5 years after T1D diagnosis if the original screen is negative (Fig. 1) [5, 6]. T1D patients with symptoms suggestive of $\mathrm{CD}$ such as unexplained weight loss (or inadequate weight gain), abdominal pain, bloating or loose stools should be tested for CD regardless of prior history of routine screening. The clinician should also be alert to the non-gastrointestinal manifestations of $\mathrm{CD}$, which include poor growth, delayed puberty, osteopenia, anemia, dental enamel defects, and depression (Fig. 2) [7]. Unexplained hypoglycemia may also be a manifestation of CD $[3,6]$. Most pediatric T1D patients who develop CD will do so within the first 5 years after T1D diagnosis although CD in adults with T1D is well recognized $[1,6]$.

Screening for CD consists of obtaining serum IgA and anti-tissue transglutaminase antibodies (anti-tTG) (Fig. 1) $[6,7]$. The anti-tTG test has a very high sensitivity and specificity with a positive predictive value of $72 \%$

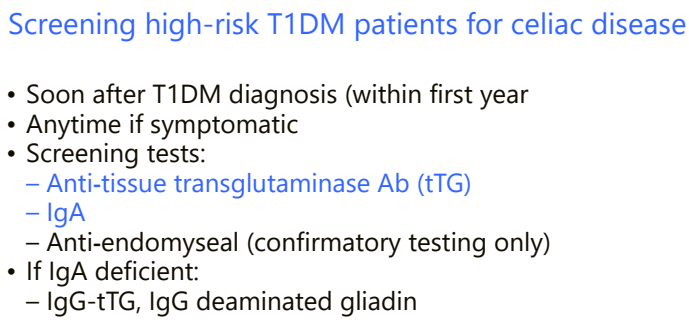

Fig. 1. Screening for celiac disease (CD) in patients with type 1 diabetes mellitus (T1DM). The American Diabetes Association recommends screening for CD shortly after diagnosis of T1DM and again at 2 and 5 years if prior screening studies are negative. T1DM patients with symptoms suggestive of $\mathrm{CD}$ should be screened with serological testing as soon as possible regardless of prior negative celiac screening. Anti-tissue transglutaminase (antitTg) and IgA are the recommended initial screening tests. If IgA deficiency is present, then IgG-tTG and/or IgG deaminated gliadin testing is recommended. Anti-endomyseal antibodies are highly sensitive and specific but are not recommended for initial screening due to cost and complexity of assay. Anti-endomyseal antibodies may be useful in T1D patients with weakly positive $(<5 \times$ upper limits of assay normal) anti-tTg screen.

[7]. Evidence-based expert recommendations suggest sending anti-endomyseal antibodies for verification of an abnormally elevated anti-tTG in the T1D population since false positive anti-tTG serologies can occur [8]. In addition, elevated anti-tTG antibodies can spontaneously revert to normal particularly when abnormal anti-tTG titers are relatively low $(<5 \times$ assay upper limit of normal) [8]. Alternatively, rare cases of biopsy proven CD with negative celiac serology have been described so clinical judgment is warranted [9].

An IgA antibody level is sent to rule out IgA deficiency because IgA-tTG is an IgA antibody, and therefore a false negative screening test could occur in a CD patient with IgA deficiency $[6,7]$. Two percent of patients with CD have IgA deficiency and patients with T1D have a 10 -fold higher risk of IgA deficiency than the general population $[7,10]$. In cases where IgA deficiency is found, celiac screening with an anti-IgG deaminated gliadin peptide (anti-DGP) is recommended (Fig. 1) [8]. Anti-DGP may also be a particularly useful celiac screening test in the $<2$ years old age group [11].

Although significantly elevated anti-tTG levels are highly predictive of $\mathrm{CD}$, the standard practice for establishing a diagnosis of CD is conferred with a small bowel biopsy $[7,8,11]$. Since the diagnosis of CD entails lifelong compliance to a gluten-free diet (GFD), it is important 
Clinical manifestations of celiac disease

Gastrointestinal-classic

- Abdominal pain

- Diarrhea/loose stools

- Abdominal distention

- Nausea/vomiting

- Constipation

Asymptomatic

common in T1D

Fig. 2. Classical gastrointestinal symptoms of celiac disease (CD) are well recognized; however, adult and pediatric patients are increasingly presenting with non-gastrointestinal or atypical symptoms. Many affected individuals are asymptomatic, especially in the type 1 diabetes population.

that a definitive diagnosis be made. The classic findings of $\mathrm{CD}$ on small bowel biopsy include increased intraepithelial lymphocytes, villous blunting, and crypt hyperplasia. The severity of pathological changes in the small bowel are reflected in the Marsh classification system [7]. Small bowel biopsy may not be necessary in select cases were anti-tTG exceeds $10 \times$ the assay upper limits of normal and symptoms of celiac as well as high risk HLA genes are present [11].

Because most patients with T1D are now routinely screened, many T1D patients are asymptomatic at the time of diagnosis $[6,8]$. There is controversy about whether asymptomatic individuals should be screened for CD because there is a lack of evidence that treating asymptomatic CD improves outcomes [12]. However, antitTG-positive patients with T1D versus anti-tTG-negative patients with T1D showed significantly lower bone density in a cross-sectional study, and another large multicenter study demonstrated lower weight and height SDS scores in T1D patients with mostly asymptomatic CD [13, 14].

T1D patients found to have findings suggestive of CD on small bowel biopsy often demonstrate resolution of their presenting GI symptoms and healing of small bowel mucosa on a GFD, although recovery may take up to 1 year or longer [15]. Counseling by a registered dietician with experience in GFD management is highly recommended for all patients with CD [16].

A study of 103 CD patients on a GFD demonstrated that up to $20 \%$ were found to have persistent enteropathy on follow-up small bowel biopsy [17]. IgA-tTG serology was not necessarily a reliable indicator of ongoing pathology or recovery in this study [17].

Type 1 Diabetes and Celiac Disease
A case control study of pediatric patients with concurrent T1D and CD from the T1D Exchange Clinic Registry showed that CD impaired linear growth in T1D females at all stages of development and that children younger at $\mathrm{CD}$ diagnosis remain shorter throughout childhood even on a GFD [18].

Notably, pediatric patients with T1D and CD did not show significant differences in hemoglobin $\mathrm{A} 1 \mathrm{c}$, rates of severe hypoglycemia, or DKA prior to diagnosis of CD [13]. However, a small study using blinded continuous glucose monitoring technology in patients with T1D and $\mathrm{CD}$ show significantly higher postprandial excursions on a GFD [19]. Postprandial hyperglycemia on a GFD may be related to the high glycemic index of refined or processed gluten-free foods [16].

Studies in adults with T1D have shown patients with $\mathrm{T} 1 \mathrm{D}$ and undiagnosed $\mathrm{CD}$ to be at significant risk for microvascular complications compared to patients with T1D alone [20]. In a study of adults with longstanding T1D screened for CD, higher prevalence rates of retinopathy, nephropathy and neuropathy were found in patients with positive screening for CD [20]. In another large multicenter cohort study of T1D, CD was found to be an independent risk factor for the development retinopathy and nephropathy [21]. In a study of patients with T1D and CD, duration of CD $>10$ years significantly increased risk for retinopathy, while $\mathrm{CD}$ patients with poor adherence to a GFD predicted early appearance of microalbuminuria [22-23]. These studies further support the recommendations of screening asymptomatic T1D patients for CD.

\section{T1D and CD Show Common Genetic Linkage}

Identical twins have an approximate 50\% risk for being concordant for T1D and a $\sim 75 \%$ risk for being concordant for celiac disorder [2]. First-degree relatives have approximately $6-8 \%$ risk for developing T1D and a $4-10 \%$ risk for developing CD - rates that are significantly higher than the general population of $1 \%$ for $\mathrm{CD}$ and $\sim 0.3 \%$ for T1D $[2,24]$. The overall T1D risk for siblings is $6-8 \%$, while the risk for children of T1D parents varies, with an affected mother estimated at $2-4 \%$ risk, while an affected father confers a greater risk 6-9\% [24]. Approximately $40-60 \%$ of the genetic risk for both disorders is due to HLA class II antigen-presenting molecules [2, 24].

HLA genes are the most highly polymorphic genes in the human genome [25]. Cell surface HLA molecules create a molecular cleft that is specific for foreign as well as

Horm Res Paediatr 2019;92:285-292 


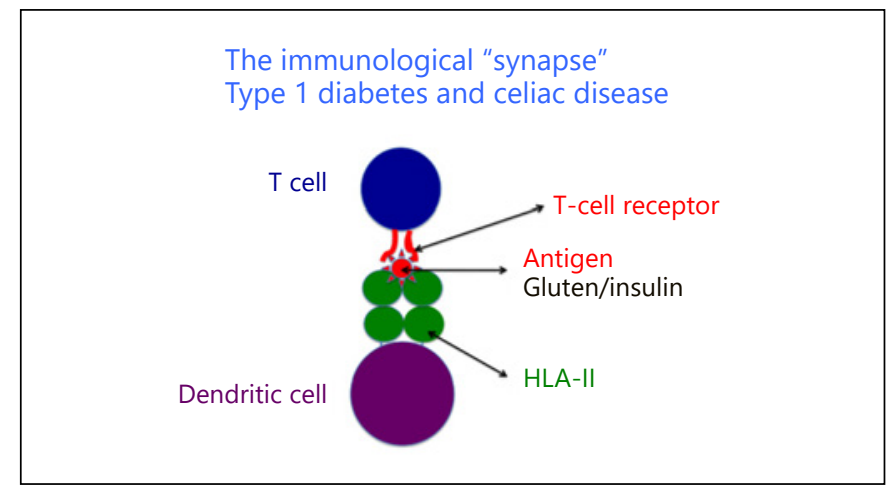

Fig. 3. Simplified schematic demonstrating the relationship between human lymphocytic antigens (HLA) with specificity for antigens (gluten or insulin). HLA molecules create a molecular cleft that is specific for foreign as well as self-antigens. HLA class II molecules are expressed on the surface of antigen presenting cells (APC or dendritic cell) and present antigens to T cells whose receptors are also specific for the same antigen. For celiac disease (CD), the antigen responsible for the autoimmune response is a group of proteins termed gluten - most commonly a 33-mer amino acid residue of gliadin. The self-antigen(s) responsible for activating the autoimmune response in type 1 diabetes mellitus (T1DM) have not been definitively proven but a likely candidate is insulin or proinsulin. For an autoimmune reaction to occur, a variety of additional factors such as costimulatory molecules on the $\mathrm{T}$ cell must be activated in addition to the presence of a proinflammatory cytokine environment. An autoimmune reaction to self-antigen(s) is referred to as "loss of tolerance." Studies in the NOD mouse model of T1D indicate that initiation of the autoimmune reaction occurs in the pancreatic lymph nodes, while in CD the autoimmune inflammatory process is occurring in the subendothelial mucosa of the small intestine.

self-antigens (Fig. 3). The shape of the binding cleft or groove and charges within the groove determine the specificity of the binding peptides [25]. HLA class II molecules are expressed on the surface of antigen presenting cells and present antigens to $\mathrm{T}$ cells whose receptors are also specific for the same antigen (Fig. 3). For CD, the antigens which bind the molecular groove of the HLA molecule that ultimately results in enteropathy are a group of proteins termed glutens, of which the 33-mer amino acid residue of gliadin is particularly pathogenic [26].

The two common HLA haplotypes leading to increased risk for both $\mathrm{CD}$ and T1D are DR4-DQ8 and DR3-DQ2 [2]. DR4-DQ8 confers increased risk of T1D, but heterozygous DR3-DQ2/DR4-DQ8 confers the greatest risk [2]. DR3-DQ2 confers greater risk for CD than DR4-DQ8, and homozygous DR3-DQ2/DR3-DQ2 confers the greatest risk. $95 \%$ of patients with CD express DR3-DQ2, while the remaining 5\% express DR4-DQ8 [7,
11]. The universal presence of these HLA haplotypes in patients with $\mathrm{CD}$ can serve as an important genetic screen in patients who lack a definitive diagnosis. The absence of both DQ2 and DQ8 effectively rules out CD $[7,11]$.

Additional genes linked to type $1 \mathrm{DM}$ such as INSVNTR, CTLA-4, PTPN 22, and up to 40 other loci contribute significant but smaller risk for T1D [24, 25]. However, increased risk for co-occurrence of T1D and CD was seen in children with a family history of T1D, genotypes HLA-DR3DQ2/DR4DQ8, HLA-DPB1, RGS1, SH2B3, CTLA-4, CCR3/CCR5, and PTPN2 [2]. The majority of genes linked to T1D and CD are related to the immune system $[24,26]$.

The high-risk HLA genes for both CD and T1D are relatively common in the general population, and the majority of individuals expressing these genes will never develop CD or T1D [24-27]. In addition, genetic risk alone could not account for the rising incidence rates of $~ 3 \%$ per year over the past several decades for T1D and also rising incidence of $\mathrm{CD}[4,26]$. Thus, environmental or epigenetic factors are implicated in the pathogenesis of both disorders [2-4, 24-27].

\section{The Immunology of T1D and CD}

$\mathrm{CD}$ is a unique autoimmune disorder in that: (1) the primary antigen that incites the disorder is known and (2) $\mathrm{CD}$ is the only autoimmune disorder that is reversible by avoiding the causative antigen in the diet [26]. The mechanism of autoimmunity in CD involves antigenic fragments of gluten crossing the small bowel epithelium directly through a leaky or damaged epithelium or through other mechanisms such as transcellular transport [26]. Glutens are highly resistant to enzymatic degradation in the gut, and high concentrations can accumulate in the lumen [26]. Once the antigenic peptides cross the small bowel epithelium into the lamina propria, they are immunologically activated by the enzyme tissue transglutaminase. Deamidation by tissue transglutaminase confers unique binding properties that enhance binding to DQ2 and DQ8 on antigen-presenting cells, which is then recognized by gluten-specific T cells. An inflammatory reaction may occur depending on the strength of the proinflammatory signals (CD4+ T cells) versus the strength of the anti-inflammatory response $(\mathrm{CD} 4+\mathrm{CD} 25+\mathrm{T}$ regulatory cells) [26].

$\mathrm{CD} 4+\mathrm{T}$ cells produce proinflammatory cytokines such as interferon-alpha and IL-17 that promote an inflammatory reaction that can stimulate immunologic de- 
struction of the small bowel epithelium [26]. Interferon can stimulate production of IL-15 from APCs, macrophages, and intestinal epithelial cells, and IL-15 is a central cytokine in inflammatory reactions. IL-15 promotes production of CD8+ T cells and CD8 + intraepithelial lymphocytes, which directly attack the small bowel enterocytes [26].

The self-antigens responsible for activating the autoimmune response in T1D have not been definitively identified but likely candidates are insulin or proinsulin, glutamic acid decarboxylase (GAD), and insulinoma antigen-2 or IA-2 [24]. Less is known about the primary antigenic stimulus in T1D because of difficulties in accessing the pancreatic lymph nodes in humans. However, a small but informative study of $\mathrm{T}$ cells obtained from the pancreatic lymph nodes of 3 patients with T1D showed that the insulin peptide fragment A1-15 stimulated $\mathrm{T}$ cells from $2 / 3$ of patients while GAD antigenic peptides did not [28].

The primary location for the initiation of the immune response in T1D in the NOD mouse model of T1D is in the pancreatic lymph nodes [29]. The pancreatic lymph nodes are the site of reaction to self-antigens from the pancreas but also to foreign antigens from the gastrointestinal tract [29]. Interestingly, studies in the NOD mouse show a direct connection between the gut and the pancreatic lymph nodes, whereby beta cell-reactive $\mathrm{T}$ cells in the pancreatic lymph nodes can be influenced by perturbations of the integrity of GI tract by agents such as indocin [29].

It is therefore temping to speculate that alterations of the GI mucosa may influence onset of T1D in humans and perhaps provide an additional explanation for the close association of CD and T1D. Infections and medications such as aspirin and ibuprofen can alter the integrity of the intestinal mucosa [30]. Antipyretic use in children genetically at increased risk for T1D in the TEDDY study did not show an association with islet autoimmunity, however [30]. Moreover, T1D most often precedes CD in patients afflicted with both disorders. In a review of 587 cases of CD and T1D, CD was diagnosed after T1D 93\% of the time [1].

In addition, the TEDDY study group prospectively examined the occurrence of islet and tissue transglutaminase (anti-tTG) antibodies as well as clinical disease in a birth cohort study of 5,891 children identified to be at high genetic risk for both disorders [2]. Islet antibodies usually (but not always) preceded the occurrence of antitTG antibodies and the average time to development of islet antibodies was 24 months of age and 33 months of

\section{Genetics and environment}

- T1DM and celiac disease strongly linked to common HLA genes but

- Most people with these same high-risk HLA genes will never

develop T1DM or celiac disease

- Incidence of T1DM and CD steadily rising implicating:

- Environmental factors linked to autoimmunity

- Viruses: (T1D)

- Diet: gluten (CD), probiotics (T1D)

- Intestinal mucosal leakiness (CD, ?T1D)

Fig. 4. Although high-risk human leukocyte antigens (HLA) DR/ DQ haplotypes have been strongly linked to type 1 diabetes mellitus (T1DM) and celiac disease (CD), these haplotypes are relatively common in the general population. In addition, the incidence rates of T1DM and CD have been increasing steadily for decades ( $\sim 3 \%$ per year). Environmental factors such as viruses, diet, leakiness of the intestinal mucosa and multiple factors influencing the microbiome have been implicated in the pathogenesis of these disorders.

age for anti-tTG. Occurrence of islet antibodies increased the risk for the development of CD antibodies. Co-occurrence of both antibodies exceeded the expected rate for each disorder independently [2]. Co-occurrence is greater than explained by demographics or common genetic risk, indicating that shared environmental or pathophysiological mechanisms may explain the increased risk [2].

\section{Environmental Factors Implicated in the Pathogenesis of T1D and CD}

\section{Viruses}

Viruses have long been suspected to play a role in the etiology of T1D with numerous reports of T1D occurring following a viral illness (Fig. 4, 5) [24]. Seasonal variation in T1D incidence has also suggested a viral etiology for T1D with higher incidence rates in the fall and winter and lower incidence in the summer [24]. A large meta-analysis of 24 studies and over 4,000 participants showed an almost 10-fold risk of RT-PCR-determined enteroviral infections in T1D patients versus controls, while another study demonstrated low-grade enterovirus infection of the pancreas of 6 newly diagnosed T1D patients and 2 of 9 controls [31, 32].

A TEDDY study of self-reported respiratory infections showed increased risk of islet autoimmunity following the common cold, flu-like illnesses, sinusitis, and tracheobronchitis [33]. Greater than 5 infections per 


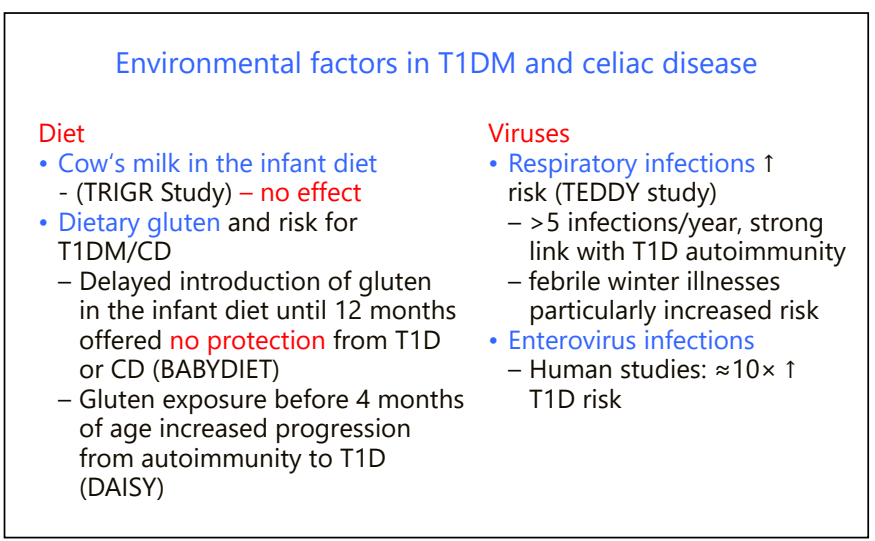

Fig. 5. Summary of the major large multicenter prospective studies examining the role of suspected dietary and infectious etiologies for type 1 diabetes (T1D) (and celiac disorder). These studies mainly addressed the risk for T1D, but the timing of the introduction of dietary gluten into the infant diet addressed the risk for both T1D and celiac disease (CD). Weaning infants to hydrolyzed infant formula had no protective effect compared to standard cow's milk-based formula (TRIGR). Delaying introduction of gluten until 12 months of age had no protective effect with follow-up of the cohort for up to 8 years (BABYDIET). Gluten exposure after 1 year had no effect on risk for T1D/CD in the DAISY study, although this study did show increased progression from T1D autoimmunity to T1D in infants exposed to gluten before 4 months of age.

9-month period preceded development of islet antibodies; winter illnesses and febrile illnesses were more likely to be associated with islet autoimmunity (Fig. 5) [33]. The high rate of beta cell antibody seroconversion (46\%) when $>5$ infections were reported could support the "fertile field" hypothesis, whereby a proinflammatory cytokine milieu or environment created by infectious illnesses is conducive to islet cell autoimmunity [33]. This study did not specifically show an increase in enteroviral infections preceding seroconversion, but the authors point out that most enteroviral infections are subclinical and therefore probably missed by self-reporting, or clinical symptoms were mild and limited to common cold-like symptoms [33].

\section{Infant Diet}

Early introduction of cow's milk into the infant's diet had been linked to T1D, with concern that bovine serum albumin may act as an antigenic trigger (Fig. 5) [24, 34]. However, a large multicenter prospective trial of infants at high risk for T1D (TRIGR) was unable to show a protective effect of infants weaned to either a hydrolyzed casein formula versus standard cow's milk formulas [34].
Concern that early introduction of gluten in the infant diet may predispose to T1D was addressed by the BABYDIET study which found no increase in islet autoimmunity or T1D when introduction of gluten was delayed out to 12 months versus 6 months in the diet of infants at risk for T1D [35]. Development of antibodies to tTG with the introduction of gluten at 6 months versus 12 months was 14 and 4\%, respectively, although the difference was not statistically significant [35]. When this cohort was followed for up to 8 years, no difference in development of T1D or CD was seen [36]. Recent results from The Diabetes Autoimmunity Study in the Young (DAISY) was also unable to show an association between gluten intake (after 1 year of age) and islet autoimmunity, although gluten intake before 4 months of age was associated with progression from islet autoimmunity to T1D [37].

\section{Gut Microbiome}

The gut microbiome is an area of increasing interest, with alterations of the microbiome being linked to a variety of human disorders including autoimmunity [38]. Diet, breastfeeding, infections, antibiotics, geographic location and method of infant delivery can lead to alterations of the microbiome $[4,26,38]$. There appears to be a continuous interplay between resident gut microbes and the immune system [38-40]. Interference in this cross talk can dramatically alter diabetes risks in the NOD mouse model of T1D [40]. A significant influence of the microbiome has been shown in the NOD mouse models of T1D, including the influence of antibiotics on increasing risk and the protective effect of fecal transplant from protected mice to mice at risk [41].

Human studies of the microbiome in children at increased risk for T1D and CD showed subtle but significant differences in cases of T1D autoimmunity versus controls [42-44]. Increased production of short-chain fatty acids appeared to confer a protective effect on T1D genetically predisposed infants and children in a large prospective study in humans according to study investigators (TEDDY) [44]. Another TEDDY study showed that supplementation of the infant diet with probiotics before 27 days of age resulted in a $60 \%$ reduction in islet autoimmunity [45].

\section{Conclusion}

The interplay between genetic predisposition and multiple predisposing environmental factors including viral infections, diet, and possibly the microbiome are in- 
volved in the pathogenesis of CD and T1D. There are likely multiple pathogenic pathways leading to clinical disease for which the precise sequence of events remains to be elucidated.

\section{Disclosure Statement}

The author has no conflict of interest to declare.

\section{References}

1 Pham-Short A, Donaghue KC, Ambler G, Phelan H, Twigg S, Craig ME. Screening for Celiac Disease in Type 1 Diabetes: A Systematic Review. Pediatrics. 2015 Jul;136(1):e1706.

2 Hagopian W, Lee HS, Liu E, Rewers M, She JX, Ziegler A. Co-occurrence of Type 1 Diabetes and Celiac Disease Autoimmunity. Pediatrics. 2017;140(5):e20171305.

3 Kaur N, Bhadada SK, Minz RW, Dayal D, Kochhar R. Interplay between Type 1 Diabetes Mellitus and Celiac Disease: implications in Treatment. Dig Dis. 2018;36(6):399-408.

4 Ludvigsson JF, Biagi F, Corazza GR. Epidemiology of Celiac Disease. In: Rampertab S, Mullin G, editors. Celiac Disease. New York: Humana Press; 2014.

5 American Diabetes Association. Children and Adolescents: Standards of Medical Care in Diabetes-2018. Diabetes Care. 2018; 41(suppl 1):S126-36.

6 Mahmud FH, Elbarbary NS, Fröhlich-Reiterer E, Holl RW, Kordonouri O, Knip M, et al. ISPAD Clinical Practice Consensus Guidelines 2018: other complications and associated conditions in children and adolescents with type 1 diabetes. Pediatr Diabetes. 2018 Oct;19 Suppl 27:275-86.

7 Tavakkoli A, Lebwohl B. Diagnosis of Celiac Disease. In: Rampertab S, Mullin G, editors. Celiac Disease. New York: Humana Press; 2014.

8 Snyder J, Butzner JD, DeFelice AR, Fasano A, Guandalini S, Liu E, et al. Evidence-Informed Expert Recommendations for the Management of Celiac Disease in Children. Pediatrics. 2016 Sep;138(3):1.

9 Schiepatti A, Sanders DS, Biagi F. Seronegative coeliac disease: clearing the diagnostic dilemma. Curr Opin Gastroenterol. 2018 May; 34(3):154-8.

10 Ludvigsson JF, Neovius M, Hammarström L. Association between IgA deficiency \& other autoimmune conditions: a population-based matched cohort study. J Clin Immunol. 2014 May;34(4):444-51.

11 Husby S, Koletzko S, Korponay-Szabó IR, Mearin ML, Phillips A, Shamir R, et al.; ESPGHAN Working Group on Coeliac Disease Diagnosis; ESPGHAN Gastroenterology Committee; European Society for Pediatric Gastroenterology, Hepatology, and Nutrition. European Society for Pediatric Gastroenterology, Hepatology, and Nutrition guidelines for the diagnosis of coeliac disease. J Pediatr Gastroenterol Nutr. 2012 Jan;54(1): 136-60.
12 Bibbins-Domingo K, Grossman DC, Curry SJ, Barry MJ, Davidson KW, Doubeni CA, et al.; US Preventive Services Task Force. Screening for Celiac Disease: US Preventive Services Task Force Recommendation Statement. JAMA. 2017 Mar;317(12):1252-7.

13 Simmons KM, McFann K, Taki I, Liu E, Klingensmith GJ, Rewers MJ, et al. Reduced Bone Mineral Density Is Associated with Celiac Disease Autoimmunity in Children with Type 1 Diabetes. J Pediatr. 2016 Feb;169:448.e1.

14 Fröhlich-Reiterer EE, Kaspers S, Hofer S, Schober E, Kordonouri O, Pozza SB, et al.; Diabetes Patienten Verlaufsdokumentationssystem-Wiss Study Group. Anthropometry, metabolic control, and follow-up in children and adolescents with type 1 diabetes mellitus and biopsy-proven celiac disease. J Pediatr. 2011 Apr;158(4):589-593.e2.

15 Herman ML, Absah I, Oxentenko AS, RubioTapia A. Monitoring and Follow-Up of patients with celiac disease. In: Rampertab S, Mullin G, editors. Celiac Disease. New York: Humana Press; 2014.

16 Simpson S, Thompson T. Nutrition in Celiac Disease. In: Rampertab S, Mullin G, editors. Celiac Disease. New York: Humana Press; 2014.

17 Leonard MM, Weir DC, DeGroote M, Mitchell PD, Singh P, Silvester JA, et al. Value of IgA tTG in Predicting Mucosal Recovery in Children With Celiac Disease on a Gluten-Free Diet. J Pediatr Gastroenterol Nutr. 2017 Feb; 64(2):286-91.

18 Simmons JH, Foster NC, Riddlesworth TD, DuBose SN, Redondo MJ, Liu E, et al.; T1D Exchange Clinic Network. Sex- and age-dependent effects of celiac disease on growth and weight gain in children with type 1 diabetes: Analysis of the type 1 diabetes Exchange Clinic Registry. Pediatr Diabetes. 2018 Jun; 19(4):741-8.

19 Pham-Short A, Donaghue KC, Ambler G, Garnett S, Craig ME. Greater postprandial glucose excursions and inadequate nutrient intake in youth with type 1 diabetes and celiac disease. Sci Rep. 2017 Mar;7(1):45286.

20 Leeds JS, Hopper AD, Hadjivassiliou M, Tesfaye S, Sanders DS. High prevalence of microvascular complications in adults with type 1 diabetes and newly diagnosed celiac disease. Diabetes Care. 2011 Oct;34(10):2158-63.
21 Rohrer TR, Wolf J, Liptay S, Zimmer KP, Fröhlich-Reiterer E, Scheuing N, et al.; DPV Initiative and the German BMBF Competence Network Diabetes Mellitus. Microvascular Complications in Childhood-Onset Type 1 Diabetes and Celiac Disease: A Multicenter Longitudinal Analysis of 56,514 $\mathrm{Pa}$ tients From the German-Austrian DPV Database. Diabetes Care. 2015 May;38(5):801-7.

22 Mollazadegan K, Kugelberg M, Montgomery SM, Sanders DS, Ludvigsson J, Ludvigsson JF. A population-based study of the risk of diabetic retinopathy in patients with type 1 diabetes and celiac disease. Diabetes Care. 2013 Feb;36(2):316-21.

23 Pham-Short A, C Donaghue K, Ambler G, K Chan A, Hing S, Cusumano J, et al. Early elevation of albumin excretion rate is associated with poor gluten-free diet adherence in young people with coeliac disease and diabetes. Diabet Med. 2014 Feb;31(2):208-12.

24 Delli AJ, Lernmark A. Type 1 (Insulin-Dependent) Diabetes Mellitus: Etiology, Pathogenesis, Prediction, and Prevention. In: Jameson JL, De Groot LJ, editors. Endocrinology: Adult and Pediatric. 7 th ed. Philadelphia: Saunders; 2016. Chapter 39. p. 672

25 Noble JA. Immunogenetics of type 1 diabetes: A comprehensive review. J Autoimmun. 2015 Nov;64:101-12.

26 Elliott DE. The Pathophysiology of Celiac Disease. In: Rampertab S, Mullin G, editors. Celiac Disease. New York: Humana Press; 2014. Chapter 4.

27 de Haas EC, Kumar V, Wijmenga C. Immunogenetics of Celiac Disease. In: Rampertab S, Mullin G, editors. Celiac Disease. New York: Humana Press; 2014. Chapter 5.

28 Kent SC, Chen Y, Bregoli L, Clemmings SM, Kenyon NS, Ricordi C, et al. Expanded T cells from pancreatic lymph nodes of type 1 diabetic subjects recognize an insulin epitope. Nature. 2005 May;435(7039):224-8.

29 Turley SJ, Lee JW, Dutton-Swain N, Mathis D, Benoist C. Endocrine self and gut non-self intersect in the pancreatic lymph nodes. Proc Natl Acad Sci USA. 2005 Dec;102(49):1772933.

30 Lundgren M, Steed LJ, Tamura R, Jonsdottir B, Gesualdo P, Crouch C, et al.; TEDDY Study Group. Analgesic antipyretic use among young children in the TEDDY study: no association with islet autoimmunity. BMC Pediatr. 2017 May;17(1):127. 
31 Yeung WC, Rawlinson WD, Craig ME. Enterovirus infection and type 1 diabetes mellitus: systematic review and meta-analysis of observational molecular studies. BMJ. 2011 Feb;342(7794):d35.

32 Krogvold L, Edwin B, Buanes T, Frisk G, Skog $\mathrm{O}$, Anagandula $\mathrm{M}$, et al. Detection of a lowgrade enteroviral infection in the islets of langerhans of living patients newly diagnosed with type 1 diabetes. Diabetes. 2015 May; 64(5):1682-7.

33 Lönnrot M, Lynch KF, Elding Larsson $H$, Lernmark $\AA$, Rewers MJ, Törn C, et al.; TEDDY Study Group. Respiratory infections are temporally associated with initiation of type 1 diabetes autoimmunity: the TEDDY study. Diabetologia. 2017 Oct;60(10):1931-40.

34 Knip M, Åkerblom HK, Al Taji E, Becker D, Bruining J, Castano L, et al.; Writing Group for the TRIGR Study Group. Effect of Hydrolyzed Infant Formula vs Conventional Formula on Risk of Type 1 Diabetes: The TRIGR Randomized Clinical Trial. JAMA. 2018 Jan; 319(1):38-48.

35 Hummel S, Pflüger M, Hummel M, Bonifacio E, Ziegler AG. Primary dietary intervention study to reduce the risk of islet autoimmunity in children at increased risk for type 1 diabetes: the BABYDIET study. Diabetes Care. 2011 Jun;34(6):1301-5.
36 Beyerlein A, Chmiel R, Hummel S, Winkler C, Bonifacio E, Ziegler AG. Timing of gluten introduction and islet autoimmunity in young children: updated results from the BABYDIET study. Diabetes Care. 2014 Sep; 37(9):e194-5.

37 Lund-Blix NA, Dong F, Mårild K, Seifert J, Barón AE, Waugh $\mathrm{KC}$, et al. Gluten Intake and Risk of Islet Autoimmunity and Progression to Type 1 Diabetes in Children at Increased Risk of the Disease: The Diabetes Autoimmunity Study in the Young (DAISY). Diabetes Care. 2019 May;42(5):789-96.

38 Lynch SV, Pedersen O. The Human Intestinal Microbiome in Health and Disease. N Engl J Med. 2016 Dec;375(24):2369-79.

39 Paun A, Yau C, Danska JS. The Influence of the Microbiome on Type 1 Diabetes. J Immunol. 2017 Jan;198(2):590-5.

40 Wen L, Ley RE, Volchkov PY, Stranges PB, Avanesyan L, Stonebraker AC, et al. Innate immunity and intestinal microbiota in the development of Type 1 diabetes. Nature. 2008 Oct;455(7216):1109-13.
41 Silverman M, Kua L, Tanca A, Pala M, Palomba $\mathrm{A}$, Tanes $\mathrm{C}$, et al. Protective major histocompatibility complex allele prevents type 1 diabetes by shaping the intestinal microbiota early in ontogeny. Proc Natl Acad Sci USA. 2017 Sep;114(36):9671-6.

42 Kostic G, Siljander V, Hyötyläinen $\mathrm{H}$, et al. The Dynamics of the Human Infant Gut Microbiome in Development and in Progression toward Type 1 Diabetes. Cell Host Microbe. 2016;20(1):121.

43 Stewart CJ, Ajami NJ, O'Brien JL, Hutchinson DS, Smith DP, Wong MC, et al. Temporal development of the gut microbiome in early childhood from the TEDDY study. Nature. 2018 Oct;562(7728):583-8.

44 Vatanen T, Franzosa EA, Schwager R, Tripathi S, Arthur TD, Vehik K, et al. The human gut microbiome in early-onset type 1 diabetes from the TEDDY study. Nature. 2018 Oct; 562(7728):589-94.

45 Uusitalo U, Liu X, Yang J, Aronsson CA, Hummel S, Butterworth M, et al.; TEDDY Study Group. Association of Early Exposure of Probiotics and Islet Autoimmunity in the TEDDY Study. JAMA Pediatr. 2016 Jan; 170(1):20-8. 